\title{
Optimum adhesive thickness in structural adhesives joints using statistical techniques based on Weibull distribution
}

\author{
José M. Arenas , Julián J. Narbón, Cristina Alía
}

\begin{abstract}
A B S T R A C T
The geometrical factors defining an adhesive joint are of great importance as its design greatly conditions the performance of the bonding. One of the most relevant geometrical factors is the thickness of the adhesive as it decisively influences the mechanical properties of the bonding and has a clear economic impact on the manufacturing processes or long runs.

The traditional mechanical joints (riveting, welding, etc.) are characterised by a predictable performance, and are very reliable in service conditions. Thus, structural adhesive joints will only be selected in industrial applications demanding mechanical requirements and adverse environmental conditions if the suitable reliability (the same or higher than the mechanical joints) is guaranteed.

For this purpose, the objective of this paper is to analyse the influence of the adhesive thickness on the mechanical behaviour of the joint and, by means of a statistical analysis based on Weibull distribution, propose the optimum thickness for the adhesive combining the best mechanical performance and high reliability. This procedure, which is applicable without a great deal of difficulty to other joints and adhesives, provides a general use for a more reliable use of adhesive bondings and, therefore, for a better and wider use in the industrial manufacturing processes.
\end{abstract}

\section{Introduction}

Adhesive bondings are most frequently used in numerous industrial sectors (automobile, shipbuilding, aeronautical, etc.) replacing or supplementing traditional joining technologies, such as welding or riveting.

Amongst the advantages of structural adhesives we can highlight their high resistance, (even under unfavourable atmospheric conditions), their lower weight, water tightness and elimination of galvanic corrosion [1]. For this reason adhesives are more frequently used in numerous manufacturing processes in different industrial sectors. Thus, in the aeronautical industry they are applied in the manufacturing of partition walls, shelves, floor panels, construction of wings or in the bonding between fuselage and wings [2,3]. In the automobile sector, they are used both in the assembly of supplementary elements (windows, windscreens, rubber joints and inside cladding) and in structural applications [4,5].

In the shipbuilding industry, adhesive is used to manufacture hermetic bondings for boat hulls, with a lower weight and higher floatability [6]. In the food sector, adhesive facilitates manufacturing lighter, more practical and cheaper containers [7].

However, in order to obtain the considerable advantages inherent to adhesives, the application in all these manufacturing processes requires a specific adhesive joint design, enhancing its performance and reducing its limitations (preparation of delicate surfaces, reduced resistance to peeling efforts, etc.). Thus, numerous research projects have been carried out in order to establish the analytical models of the structural adhesive joints to allow learning more on the performance of the adhesives and to provide criteria to optimise the design of the adhesive joints $[8,9]$. When the geometry of the joint is complex, many researchers have used the finite elements method for the simulation of the performance of adhesive joints [10-13].

The geometry of the structural adhesive joint is a very important aspect in the design of the joint as it greatly conditions its service performance $[14,15]$. One of the most relevant geometrical factors is the thickness of the adhesive as it decisively influences the mechanical properties of the long production runs. A series of investigations have been made in order to determine the influence of the adhesive in the resistance of the joint using analytical models [16,17], simulation by finite elements $[18,19]$ and/or experimental tests $[20,21]$. However, the effect of the adhesive thickness on the bond strength of single-lap adhesive joints is still not perfectly understood. The classical elastic analyses predict that the strength increases with the adhesive 
thickness, whereas experimental results show the opposite. Various theories have been proposed to explain this discrepancy. Adams and Peppiatt [22] attribute the joint strength decrease with adhesive thickness to the fact that thicker bondlines contain more defects such as voids and microcracks. Crocombe [11] explains that as the adhesive gets thicker, the plastic spreading of the adhesive along the overlap occurs more rapidly. Interface stresses were shown to be higher for thicker bondlines by Gleich et al. [23] and da Silva et al. [20]. More recently, Grant et al. [19] explained the influence of the adhesive thickness with the bending moment.

Although prior research and analyses provide a good guidance for the prediction of the error in structural adhesive joints they are not, however, sufficient to assess the degree of adaptation of said joint to the manufacturing process or long production runs and do not provide in-depth knowledge on their reliability in service conditions. Therefore, the evaluation of the global idealness of a structural adhesive joint requires considering, in addition, factors relative to production costs (preparation time and carrying out, equipment and tooling necessary, etc.), health and safety in the assembly operations, environmental impact (low volume and low-level contaminanting waste material) and the reliability of the joint [24]. This last factor is of special relevance in order to achieve a better and wider use of structural adhesive joints in industrial applications. The traditional mechanical joints (riveting, welding, etc.) are characterised by a predictable performance, and very reliable in service conditions. Thus, structural adhesive joints will only be selected in industrial applications with demanding mechanical requirements and adverse environmental conditions if the suitable reliability (the same or higher as mechanical joints) is guaranteed. An experimental procedure that can be suitable for precisely assessing the reliability of an adhesive joint is the Weibull statistical method [25]. Towse et al. [26] have used this method for the estimation of the strength in selected points of the joint and assess the effect of small variations in the local geometry on the failure prediction in an idealised section of an adhesive joint.

Therefore, the purpose of the present paper is the analysis of the influence of the thickness of the adhesive on the mechanical performance of the joint and, by means of a statistical analysis based on Weibull distribution, to propose the optimum thickness of the adhesive that combines the best mechanical performance with high reliability.

\section{Methodology}

\subsection{Material, equipment and tooling}

In order to demonstrate the procedure, one of the most widely used structural adhesive joints has been selected: single overlap aluminium joint with acrylic adhesive, widely used in the automobile and aeronautical sectors, where light and resistant structures are required.

The substrates correspond to a 6160 aluminium alloy measuring $100 \times 25 \times 2$ (in mm). Fig. 1 shows the single lap joint with the respective dimensions. The original surface finish of the aluminium corresponds to a lamination process and its roughness $R_{\mathrm{a}}$ is $0.5 \mu \mathrm{m}$.

Taking into account the material of the substrates and the shear stress to which the adhesive will be subjected, an anaerobic structural mono-component and high viscosity adhesive was chosen (Henkel Loctite ${ }^{\circledR}$ 330; Henkel, Munich, Germany). This adhesive cures between the mounted parts aided by of an activator (Loctite ${ }^{\circledR}$ activator 7388; Henkel, Munich, Germany). Properties of structural adhesive: specific weight a $25^{\circ} \mathrm{C}$ is 1.05 ; viscosity brookfield RVT $25^{\circ} \mathrm{C}$ between 46000 and $90000 \mathrm{mPas}$ and viscosity DIN $54453 . \mathrm{SV} .25^{\circ} \mathrm{C}$ between 30000 and $70000 \mathrm{mPas}$.

One of the most delicate aspects in the assembly of an adhesive joint is that concerning the surface preparation of the substratum. For the cleaning and degreasing of the surface of the substrates MEK (Methyl Ethyl Ketone) was used. The degreasing procedure started with the cleaning of the surfaces of each substrate with absorbent paper, wetted with MEK to eliminate the dirt and grease. Then, water was applied on the treated surface with a spray. After that, a stream of hot air was applied to the surface from a drier in order to leave the surface dry and clean.

In order to ensure the necessary repetition of the experiments and maintain the geometrical parameters invariable (overlap length and adhesive thickness), a polyethylene assembly tool was utilised, adjustable with plastic shims that allow obtaining the desired thickness of the adhesive with great precision (precision of $\pm 0.01 \mathrm{~mm}$ ) and has a stable support during the resting time $(2 \mathrm{~h})$. Fig. 2 shows the polyethylene mould used to manufacture the single lap joints.

After, in the stage of curing, it is very important to maintain the same environmental conditions (temperature and relative

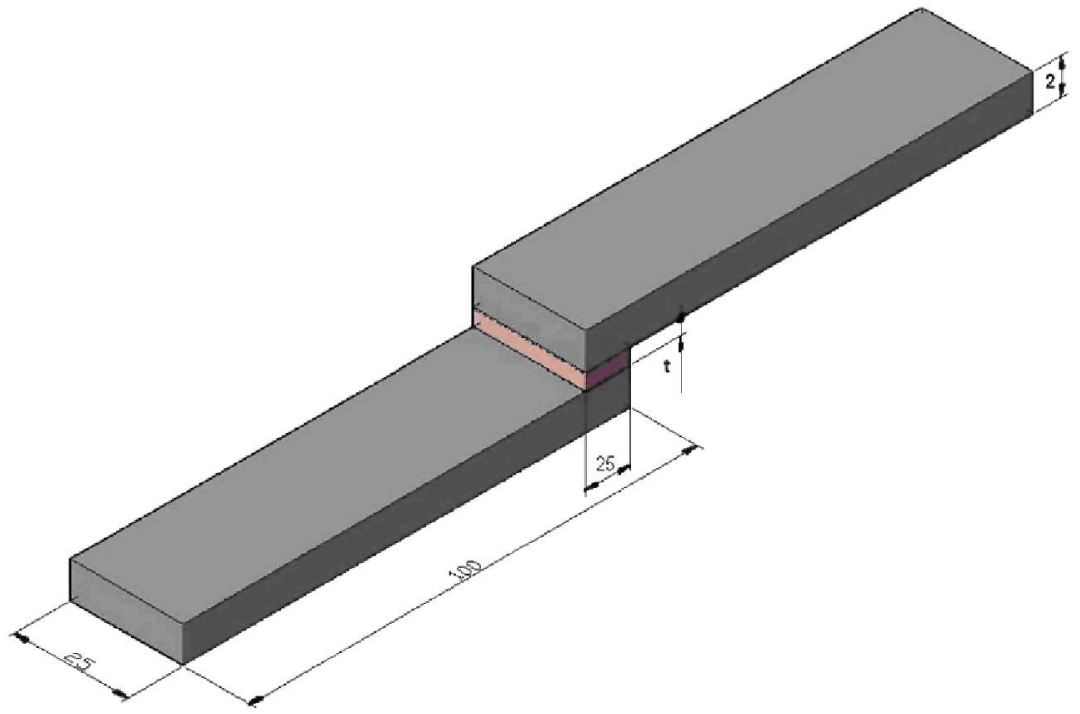

Fig. 1. Geometrical parameters of the single lap joint (dimensions in mm). 

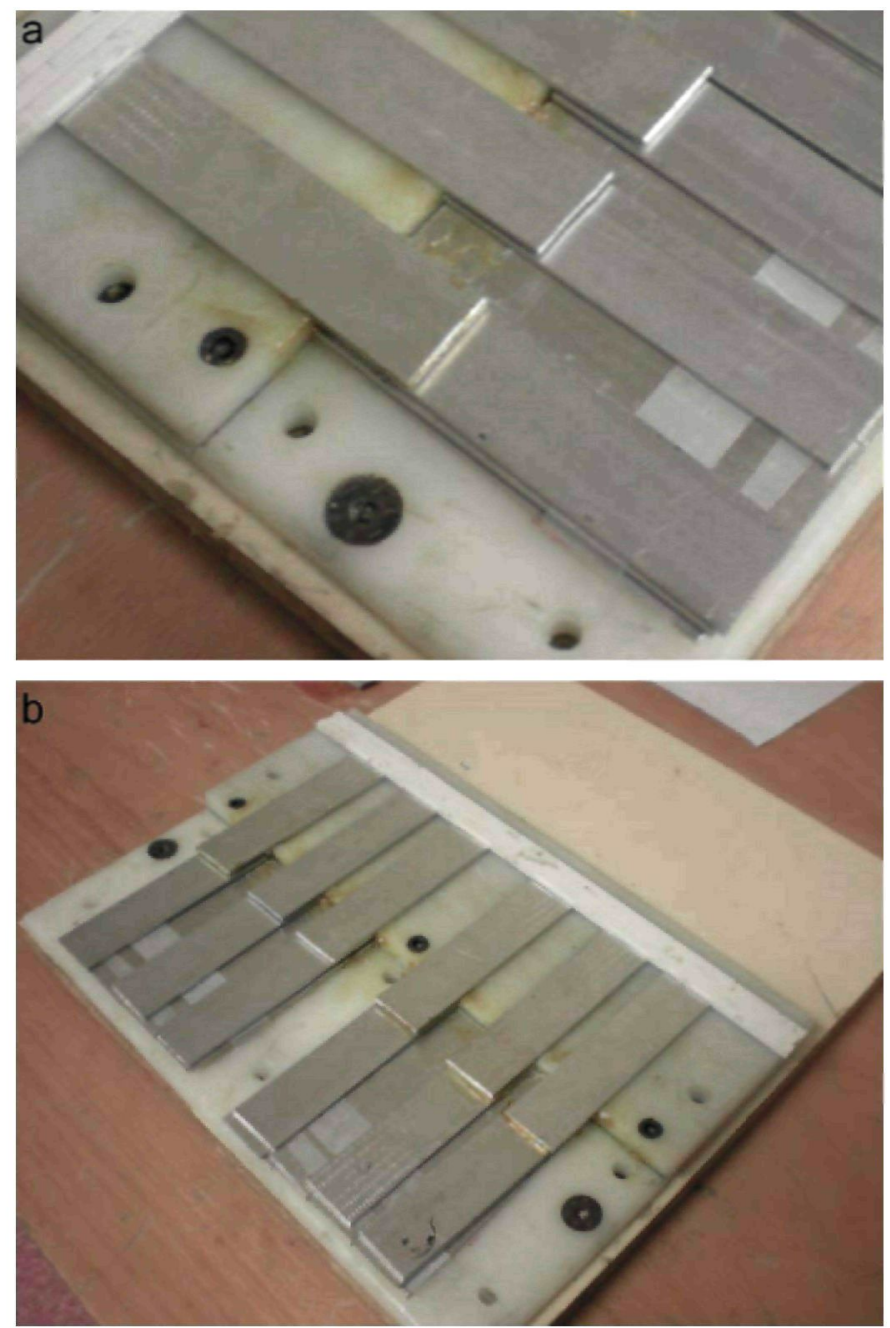

Fig. 2. Mould used to fabricate the single lap joints. (a) Detail of joint assembly in the mould; (b) mould used with 6 specimens.

humidity). By means of the acclimatisation of the room, the temperature was kept stable $\left(25 \pm 0.4^{\circ} \mathrm{C}\right)$. As the relative humidity is a critical factor on the joint strength, a dry chamber was utilised for the homogeneous curing of the adhesive. The chamber included silica gel (in spheres of a diameter of between 2 and $5 \mathrm{~mm}$ ) and a filter to collect the humidity, chlorine-free and biodegradable, with a saturation indicator. The chamber also included a support perforated for the filter and a thermohygrometer for monitoring purposes during the curing time. Inside the chamber, the relative humidity was kept between 34 and $36 \%$ for the entire curing time $(72 \mathrm{~h})$.

After the curing time, the joints were removed from the chamber. A dimensional verification was carried out with a digital gauge and the tensile test was conducted after test. For the tensile tests, a model TN-MD machine (HOYTOM, S.L., Bilbao, Spain) motorised with automatic control via a computer was used. Its capacity is $200 \mathrm{kN}$, the piston stroke length is $125 \mathrm{~mm}$ and the displacement rate was fixed at $2 \mathrm{~mm} / \mathrm{min}$. Tab ends were used to improve joint alignment (Fig. 3).

\subsection{Manufacture of the single lap joints}

The repeatability of the experiments was assured with a strict control of the environmental conditions, temperature and

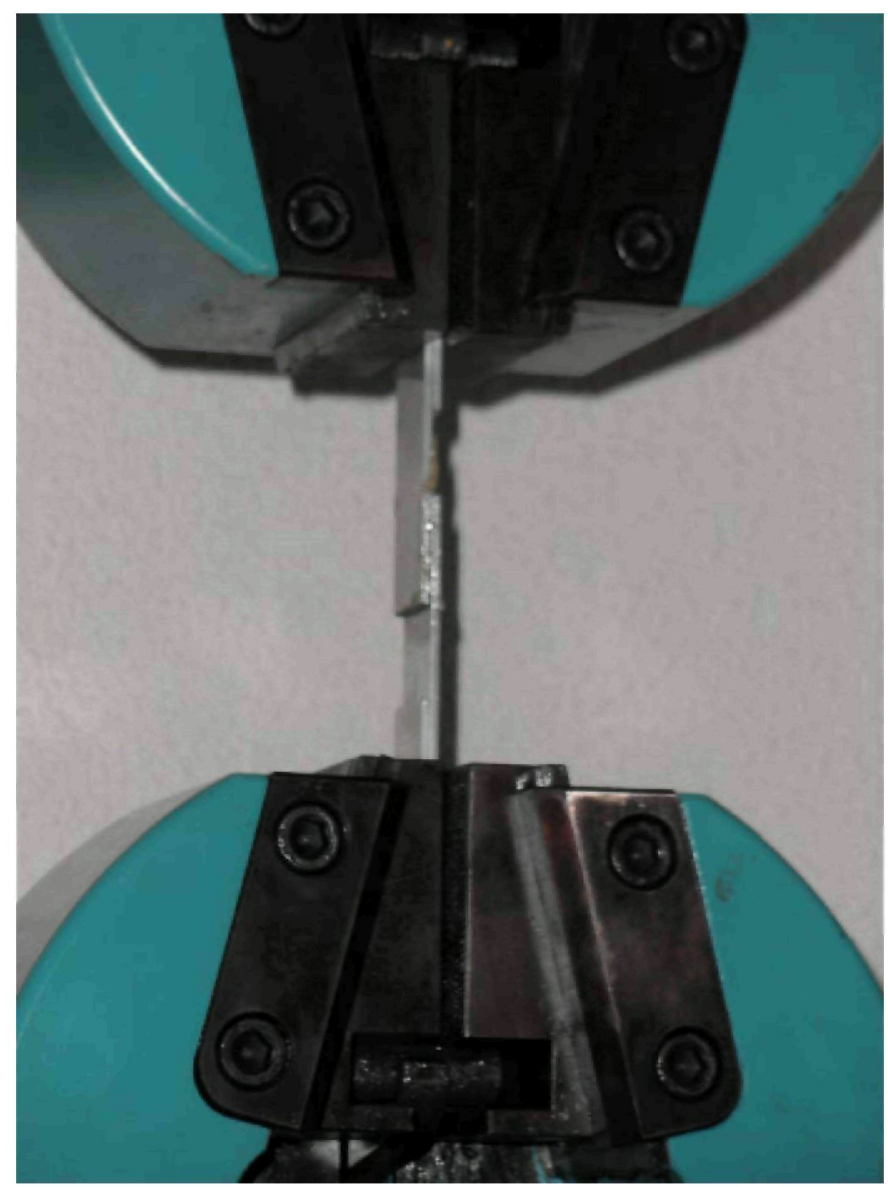

Fig. 3. Experimental set up.

humidity among others, in our laboratory:

- Laboratory: relative humidity of $44 \pm 6 \%$ and temperature of $25 \pm 0.4^{\circ} \mathrm{C}$

- Curing chamber: relative humidity of $35 \pm 1 \%$ and temperature of $26 \pm 1^{\circ} \mathrm{C}$.

The polyethylene assembly tool was gauged to achieve the desired adhesive thickness, after the aluminium substrates were prepared. The lower substrate, located in the assembly tool, receives the adhesive (with the manual dosifier) and the other substrate receives the activator (with spray) before being placed on the tool. Once assembled, the excess adhesive was removed (to avoid possible origins of fractures) and a $0.250 \mathrm{~kg}$ weight was placed on the joint for $2 \mathrm{~h}$. After this time, the joints were placed in the homogeneous curing chamber for the polymerisation of the adhesive for $72 \mathrm{~h}$.

\subsection{Tensile tests}

The experimental study consisted of a shear tensile strength test of 20 samples representative of each thickness of adhesive considered ( 7 thicknesses of between 0.2 and $0.8 \mathrm{~mm}$ ) following standard UNE-EN 1465 on the determination of the shear strength of single lap joints adhesively bonded with rigid substrates [27].

\section{Results}

In the tests carried out, the load/displacement curves were linear until failure. Fig. 4 shows the load/displacement curve, 
shear stress-strain curve and the failure surface for one adhesive thickness case $(0.5 \mathrm{~mm})$ for illustrate purposes.

Table 1 shows the values obtained from the shear strength ( $\tau$ : failure load/bonded area) and failure mode for each adhesive thickness. Fig. 5 shows a graph with the variation of the shear strength (in MPa) as a function of adhesive thickness used. The following conclusions can be drawn from this figure:

a) For thicknesses between 0.8 and $0.4 \mathrm{~mm}$, the shears are essentially cohesive and the average value of the shear

a

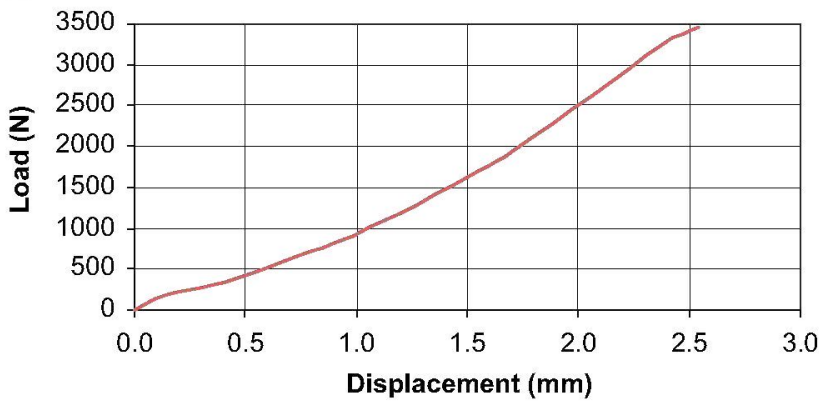

b

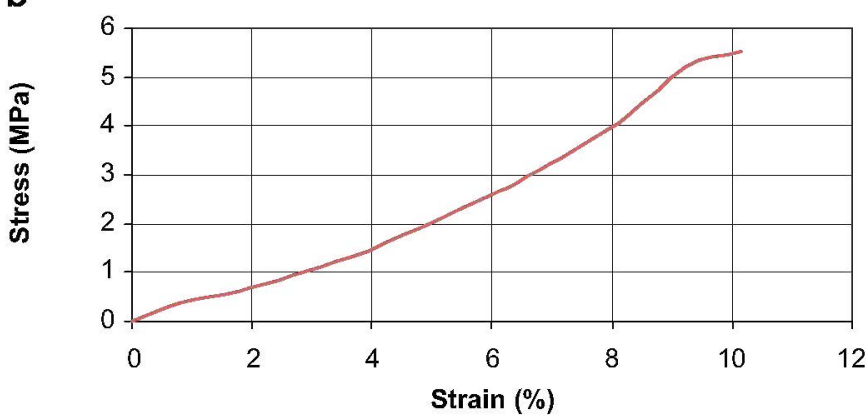

C

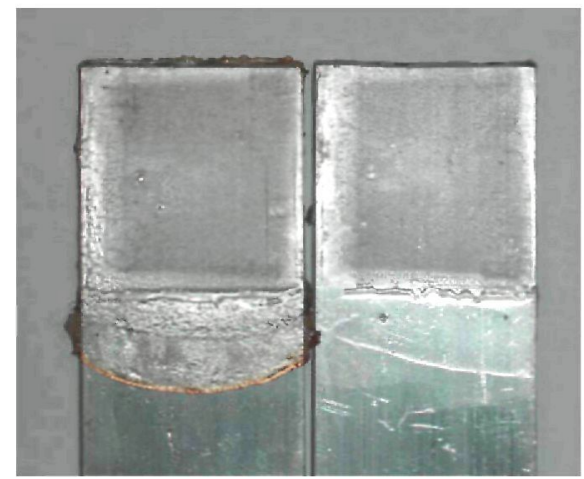

Fig. 4. Load-displacement curve (a), shear stress-strain curve (b) and failure surface (cohesive) (c) for one adhesive thickness case $(0.5 \mathrm{~mm})$. strength increases as the thickness of the adhesive is reduced. In our test, this behaviour can be principally explained because, when the thickness of the adhesive reduces, the adhesive contains less defects (voids, microcracks, etc.) and, therefore, the shear stress increases. Additionally, it can also influence in this increase of the shear stress that the plastic spreading of the adhesive along the overlap occurs more rapidly when adhesive thickness increases and that the interface stresses are higher for thicker bondlines.

b) For adhesive thicknesses of less than $0.4 \mathrm{~mm}$ the adhesive failure mode increases considerably. The shear strength presents higher values (with a high typical deviation) but, after reaching a maximum, it starts to decrease. In this range of thicknesses it is foreseeable that the cohesive resistance of the adhesive has continued with its increase with the decrease of the thickness until the adhesive-substratum attraction resistance in the interface has been exceeded. In this situation, the shear essentially depends on the adhesive resistance of the union in the interface.

As the adhesive shear modes are not very predictable as they depend on a large number of factors that can very rarely be fully monitored, the design of the adhesive joint is carried out with cohesive shear in mind. This shear basically depends on the adhesive characteristics (which are well known) and therefore, there is higher confidence on the foreseeable resistance of the joint under working conditions. Thus, in the considered application, the most suitable range of the thicknesses of the adhesive is between 0.8 and $0.4 \mathrm{~mm}$.

In addition, minimum shear strength is an important parameter for the practical application of an adhesive joint in manufacturing processes as it is used as a use-selective parameter. In the tests carried out, the maximum value of this parameter is very similar for the thicknesses of 0.4 and $0.5 \mathrm{~mm}$, making the choice between them difficult.

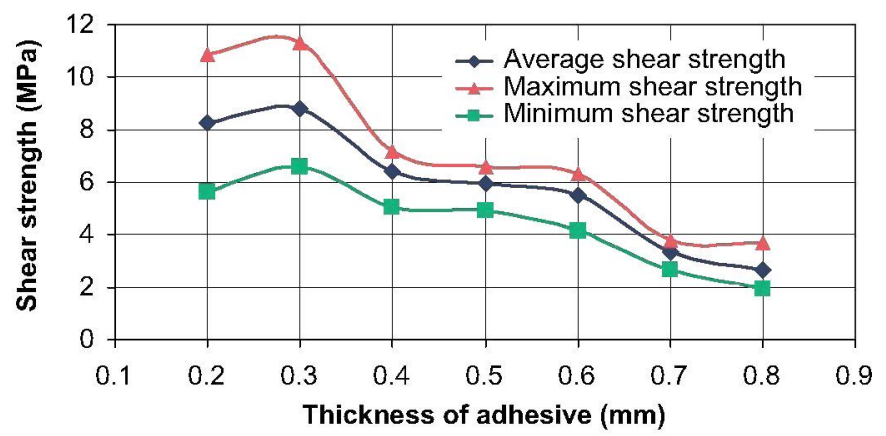

Fig. 5. Shear strength as a function of the adhesive thickness used.

Table 1.

Shear strength values and type of failure for each adhesive thickness.

\begin{tabular}{|c|c|c|c|c|c|c|c|}
\hline Thickness (mm) & \multicolumn{4}{|c|}{ Shear strength $\tau$ (MPa) } & \multicolumn{3}{|c|}{ Failure mode (\%) } \\
\hline 0.4 & 7.18 & 5.04 & 6.40 & 0.56 & 90 & 0 & 10 \\
\hline 0.5 & 6.59 & 4.93 & 5.96 & 0.47 & 100 & 0 & 0 \\
\hline 0.6 & 6.33 & 4.16 & 5.49 & 0.61 & 100 & 0 & 0 \\
\hline
\end{tabular}


The previous results can be sufficient in some applications that are not critical for the operation and safety of the product. However, when the structural adhesive joint is subject to demanding mechanical requirements and the guarantee for a suitable reliability is required, the previous results are insufficient. For this, the adhesive joint is normally over-dimensioned or hybrid bondings are introduced in order to ensure correct operation. In either case, this is translated into a higher number of assembly activities and increase in costs (longer assembly time, more adhesive or addition or mechanical bonding elements, etc.) that limit the use of structural adhesives in manufacturing processes.

Thus, it is necessary to carry out more a comprehensive statistical study which, based on the Weibull method, allows defining the optimum thickness of the adhesive that best combines good mechanical performance together with high reliability.

\section{Analysis and discussion}

Weibull distribution is applicable for reliability analysis in small-sized samples. Weibull [25] proposed a cumulative failure distribution function $F(t)$ which, applied to this case, can be shown as follows:

$F(t)=1-\exp \left[-\left(\frac{F-F_{0}}{\eta}\right)^{\beta}\right]$

where $F(t)$ is probability of the failure with force $F, F$ is applied force, $F_{o}$ is force threshold below which the probability of failure is zero, $\eta$ is scale parameter and $\beta$ is Weibull module.

If for improved reliability we take $F_{o}=0$ and double logarithms are used, Eq. (1) results as follows:

$Y=\ln \ln \left(\frac{1}{1-F(t)}\right)=\beta \ln F-\beta \ln \eta$

If we represent $Y$ against $\ln F$, the slope of the straight obtained by the least squares method provides an estimation of the reliability of the adhesive joint. Its application to the sample results obtained in the tests allows verifying that the data allow a linear regression adjustment and comply with the Weibull model. Table 2 shows the linear regression equations, the linear correlation coefficient (good in all the cases) and the value of the Weibull module. Fig. 6 includes the variation of the Weibull module depending on the thickness of the adhesive, demonstrating that there is a maximum for $0.5 \mathrm{~mm}$ (Weibull module is 13.964).

Therefore, we can conclude that the thickness of the adhesive with the highest reliability is $0.5 \mathrm{~mm}$, the expected tensile shear strength average is $5.96 \mathrm{MPa}$.

Table 2.

Results of the application of the Weibull model.

\begin{tabular}{lllc}
\hline Thickness $(\mathrm{mm})$ & Equation & Correlation coeff. & $\begin{array}{c}\text { Module of } \\
\text { Weibull }\end{array}$ \\
\hline 0.2 & $\mathrm{y}=5.6635 \mathrm{x}-\mathbf{1 2 . 2 8 4}$ & 0.9672 & 5.6635 \\
0.3 & $\mathrm{y}=6.6985 \mathrm{x}-\mathbf{1 4 . 8 9 1}$ & 0.9463 & 6.6985 \\
0.4 & $\mathrm{y}=12.232 \mathrm{x}-23.088$ & 0.9576 & 12.232 \\
0.5 & $\mathrm{y}=13.964 \mathrm{x}-25.319$ & 0.9758 & 13.964 \\
0.6 & $\mathrm{y}=9.554 \mathrm{x}-16.633$ & 0.9537 & 9.554 \\
0.7 & $\mathrm{y}=11.411 \mathrm{x}-14.089$ & 0.9785 & $\mathbf{1 1 . 4 1 1}$ \\
0.8 & $\mathrm{y}=7.5534 \mathrm{x}-7.7463$ & 0.9504 & 7.5534 \\
\hline
\end{tabular}

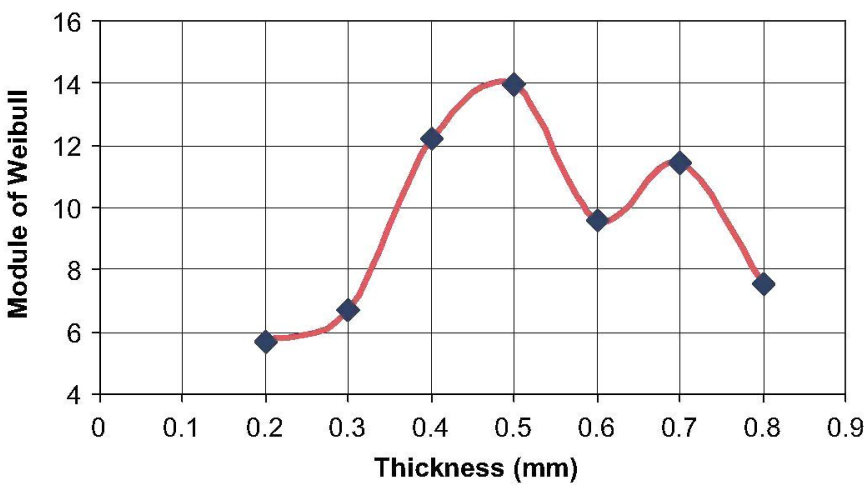

Fig. 6. Variation of the Weibull module depending on adhesive thickness.

\section{Conclusions}

The work carried out analyses the influence of the thickness of the adhesive on the tensile lap-shear strength of single overlap joints. For thicknesses between 0.8 and $0.4 \mathrm{~mm}$, with essentially cohesive shears, the average value of the shear strength increases as the thickness of the adhesive is reduced. For adhesive thicknesses of less than $0.4 \mathrm{~mm}$, with an essentially adhesive failure mode, the shear strength shows higher values but with a high typical deviation.

As the adhesive shear mode is not very predictable, the selection of the thickness of the adhesive joint should be carried out within the cohesive failure range (between 0.4 and $0.8 \mathrm{~mm}$ ) as this shear basically depends on the adhesive characteristics (which are well known) and, therefore, there is greater reliability on the foreseeable resistance of the joint under working conditions. A relevant parameter to select the best thickness in this cohesive failure range is the minimum value of the shear strength. In the tests carried out, the maximum value of this parameter is very similar for the thicknesses of 0.4 and $0.5 \mathrm{~mm}$, making the choice between them difficult.

The previous results show the performance of the structural adhesive joint depending on the thickness of the adhesive and provide good guidance to establish the most suitable dimensional range for the adhesive thickness. However, when the structural adhesive joint is subject to demanding mechanical requirements and the guarantee for a suitable reliability is required, the previous results are insufficient. Thus, the present paper proposes the use of Weibull distribution in order to make the design of more reliable structural adhesive joints easier.

The use of Weibull distribution allows selecting the most suitable thickness combining good mechanical performance and high reliability. In the practical case carried out, the Weibull application has allowed setting $0.5 \mathrm{~mm}$ as the optimum adhesive thickness.

The procedure described, easily applicable to other joints and adhesives, provides a general method for a more reliable use of adhesive bondings, and therefore, for their improved and wider use in industrial manufacturing processes.

\section{Acknowledgements}

The authors would like to thank Dr. Mario Madrid from Henkel for providing the adhesive used in the work and to the Autonomous Community of Madrid for the financing obtained for this project. 


\section{References}

[1] Adams RD, Comyn J, Wake WC. Structural adhesive joints in engineering. London: Chapman \& Hall; 1997.

[2] Ruschau IJ, Coate JE. The effectiveness of an adhesively bonded composite patch as applied to a transport aircraft lower wing skin. Int Soc Adv Mater and Process Eng Symp 1994:532-43.

[3] Guyt C. Delamination effects in fuselage crack patching. Int Soc Adv Mater Process Eng Symp 1996:903-14.

[4] Satoh T, Miyazaki Y, Suzukawa Y, Nakazato K. On the development of structural adhesive technology for the automotive body in Japan. JSAE J $1996 ; 17: 165-78$.

[5] Schroeder KJ. Structural adhesives for aluminium vehicles. SAE Trans 1996;105(5):195-202.

[6] SIKA Industry. Prontuario de productos. Madrid; 1999.

[7] Liesa F, Bilurbina L. Adhesivos industriales. S.A., Barcelona: Marcombo; 1990

[8] Da Silva LFM, das Neves PJC, Adams RD, Spelt JK. Analytical models of adhesively bonded joints - Part I: literatue survey. Int J Adhes Adhes 2009;29:319-30.

[9] Da Silva LFM, das Neves PJC, Adams RD, Wang A, Spelt JK. Analytical models of adhesively bonded joints-Part II: comparative study. Int I Adhes Adhes 2009;29:331-41.

[10] Harris JA, Adams RA. Strength prediction of bonded single lap joints by nonlinear finite element methods. Int J Adhes Adhes 1984;4(2):65-78.

[11] Crocombe $\mathrm{AD}$. Global yielding as a failure criterion for bonded joints. Int J Adhes Adhes 1989;9(3):145-53.

[12] Belingardi G, Goglio L, Tarditi A. Investigating the effect of spew and chamfer size on the stresses in metal/plastics adhesive joints. Int J Adhes Adhes $2002 ; 22(4): 273-82$.

[13] Andreassi L, Baudille R, Biancolini ME. Spew formation in a single lap joint. Int J Adhes Adhes 2007;27(6):458-68.

[14] Arenas JM, González $C$, Guillamón A, Sebastián MA. Diseño de uniones adhesivas estructurales. Ing Quím 2002;396:93-102.

[15] Arenas JM, Guillamón A. Diseño asistido por ordenador de uniones adhesivas estructurales para instalaciones de ingeniería. Ing Quím 2008;461:116-21.
[16] Bigwood DA, Crocombe AD. Elastic analysis and engineering design formulae for bonded joints. Int J Adhes Adhes 1989;9(4):229-42.

[17] Adams RD, Mallick V. A method for the stress analysis of lap joints. J Adhes 1992;38(3):199-217

[18] Kahraman R, Sunar M, Yilbas B. Influence of adhesive thickness and filler content on the mechanical performance of aluminium single lap-joints bonded with aluminium powder filled epoxi adhesive. J Mater Process Tech 2008;205:183-9.

[19] Grant LDR, Adams RD, da Silva LFM. Experimental and numerical analysis of single-lap joints for the automotive industry. Int $J$ Adhes Adhes $2009 ; 29(4): 405-13$.

[20] Da Silva LFM, Rodrigues TNSS, Figueiredo MAV, de Moura MFSF, Chousal JAG. Effect of Adhesive Type and Thickness on the Lap Shear Strength. J Adhes 2006;82(11):1091-115.

[21] Da Silva LFM, Carbas RJC, Critchlowb GW, Figueiredo MAV, Brownc K. Effect of material, geometry, surface treatment and environment on the shear strength of single lap joints, Int J Adhes Adhes doi:10.1016/j.jjadhadh.2009. 02.012.

[22] Adams RD, Peppiatt NA. Stress analysis of adhesively bonded lap joints. J Strain Anal Eng 1974;9:185-96.

[23] Gleich DM, van Tooren MJL, Beukers A. Analysis and evaluation of bondline thickness effects on failure load in adhesively bonded structures. J Adhes Sci Technol 2001;15(9):1091-101.

[24] Arenas JM, Narbón JJ, Alía C. Influence of the surface finish on the shear strength of structural adhesive joints and application criteria in manufacturing processes. J Adhes 2009;85(6):324-40.

[25] INSHT. NTP 331: Fiabilidad: la distribución de Weibull. Centro Nacional de Condiciones de Trabajo. Instituto Nacional de Seguridad e Higiene en el Trabajo; 1994.

[26] Towse A, Potter KD, Wisnom MR, Adams RD. The sensitivity of a Weibull failure criterion to singularity strength and local geometry variations. Int J Adhes Adhes 1999;19(1):71-82.

[27] AENOR. UNE-EN 1465: Adhesivos: determinación de la resistencia a cizalladura por tracción de juntas pegadas de sustratos rígidos. Asociación española de normalización; 1996. 